\title{
Gestão de design e cultura organizacional: diagnóstico de uma microempresa de estofados
}

\author{
Design management and organizational culture: diagnosis of an \\ upholstery microenterprise
}

FORCELINI, Franciele

Universidade Federal de Santa Catarina - UFSC I francieleforcelini@gmail.com

VARNIER, Thiago

Universidade Federal de Santa Catarina - UFSC I thiagovarnier1@gmail.com

MERINO, Giselle Schmidt Alves Díaz

Universidade Federal de Santa Catarina - UFSC I gisellemerino@gmail.com

MERINO, Eugenio Andrés Díaz

Universidade Federal de Santa Catarina - UFSC I eugenio.merino@ufsc.br

\begin{abstract}
Resumo
O desenvolvimento de uma cultura Abstract

organizacional voltada ao design é uma estratégia de diferenciação para as empresas. Portanto, este artigo se propõe a diagnosticar a cultura organizacional de uma microempresa de estofados como forma de identificar potencialidades e fragilidades para inserção da gestão de design. Caracteriza-se como um estudo qualitativo, exploratório e descritivo, por meio de um estudo de caso. Os resultados apontam uma posição favorável da empresa quanto a inserção da gestão de design.

The development of an organizational culture focused on design is a differentiation strategy for companies. Thus, this paper proposes to arrange an organizational culture for an upholstery microenterprise as a means to identify strengths and weaknesses for the implementation of the design management. It is a qualitative, exploratory and descriptive study, which takes place through a case study. Results point to a favorable position of the company regarding the design management application.
\end{abstract}

Palavras-chave: Design. Gestão de design. Cultura organizacional. Micro e pequenas empresas.

Keywords: Design. Design management. Organizational culture. Micro and small businesses. 


\section{INTRODUC̣ÃO}

Decorrente ao crescente empreendedorismo no Brasil, torna-se visível o aumento do número de micro e pequenas empresas (MPEs) e a sua participação na economia. Os dados do SEBRAE (2015) apontam cerca de 9,5 milhões de MPEs no país, que representam mais da metade dos empregos formais. Diante disso, no cenário econômico marcado por inovações e mudanças mercadológicas, estas empresas necessitam manter-se atualizadas e, muitas vezes, reestruturar-se (internas e externamente) para permanecerem ativas e competitivas.

Martins e Merino (2011) destacam a competitividade como propulsora do emprego do design, não apenas na concepção estética, mas também estratégica, passando por todas as fases do desenvolvimento organizacional. Ainda, ressaltam que nas últimas décadas o design vem redefinindo suas funções, ganhando o status de atividade estratégica, intitulada gestão de design. Neumeier (2010) corrobora apresentando a abrangência do design por meio do viés do desempenho. Deste modo, a gestão de design pode ser entendida como um meio de evidenciar os valores existentes, bem como gerar novos diferenciais competitivos nas empresas, atendendo as crescentes expectativas e exigências de seus clientes.

Merino e Ogava (2012) destacam a inovação como um dos mais determinantes fatores para o fortalecimento das empresas, bem como, para a sua diferenciação mercadológica. Não obstante, apontam a dificuldade dos gestores de MPEs compreenderem como do design e da inovação podem ser inseridos neste contexto. Para Bes e Kotler (2011) há uma lacuna entre a necessidade e a capacidade de inovar, onde grande parte dos gestores entende a relevância da criatividade, mas poucos conseguem torná-la parte integrante de suas empresas.

Assim, percebe-se a existência de um ambiente propício para a inserção das ferramentas da gestão de design, capazes de estimular a economia criativa e gerar valores tangíveis e intangíveis para as empresas. Para Neumeier (2010), a empresa tradicional e sua mentalidade rígida não consegue tratar dos problemas capciosos do presente e, portanto, necessitam de uma visão holística e humanizada.

Nesse sentido, Best (2012), Mozota, Klöpsch e Costa (2011) ressaltam o design a partir de seu poder diferenciador, integrador, transformador e também como um bom negócio, sendo uma estratégia para as empresas que buscam diferenciais competitivos e inovações. Best (2012) destaca ainda a capacidade do design englobar várias áreas a partir de uma abordagem centrada nas pessoas. No entanto, nota-se um desconhecimento sobre o que é a gestão de design e como pode ser inserida na cultura organizacional das empresas. 
A este respeito, Robbins e Judge (2014) abordam a cultura organizacional como a união de valores estratégicos e culturais da empresa, que resultam na sua diferenciação em relação aos concorrentes. Griffin e Moorhead (2006) ressaltam a importância de se desenvolver uma cultura organizacional e a associam o seu êxito às suas ações, estratégias e ao modo que desenvolvem a sua cultura. Nesse sentido, Best (2012) destaca que exercer maior influência nas indústrias criativas, compreender os desafios e as oportunidades inerentes às diferentes culturas organizacionais constitui uma notável vantagem.

Com base no exposto, o artigo tem como problemática: Como identificar as potencialidades e fragilidades da cultura organizacional no que tange a inserção da gestão de design em uma microempresa de estofados? Para tanto, o objetivo geral consiste em diagnosticar a cultura organizacional de uma microempresa de estofados da região do Vale do Itajaí, Santa Catarina, como forma de identificar potencialidades e fragilidades para a inserção da gestão de design. Neste trabalho, a empresa estudada não será identificada.

Este artigo justifica-se por razões práticas por propiciar aos gestores o entendimento das características da cultura organizacional de suas empresas, auxiliando na elaboração de estratégias para a inserção da gestão de design. A aplicação em MPEs justifica-se pela relevância da categoria e pela necessidade de manterem-se competitivas e preparadas para as novas exigências (SEBRAE, 2015). Ressalta-se ainda a importância econômica e social do setor de transformação que, segundo o SEBRAE (2013), é o de maior representatividade na geração de empregos na macrorregião do Vale do Itajaí, correspondendo a $49.7 \%$.

Martins e Merino (2011) destacam que ações de incentivo para a inserção do design nas empresas possibilitam novos produtos e processos, bem como o fortalecimento da sua imagem corporativa. Contudo, percebe-se uma carência de constructos teóricos que investiguem as relações entre a cultura organizacional e a gestão de design nas empresas.

\section{CULTURA ORGANIZACIONAL}

Cultura Organizacional refere-se a um sistema de valores compartilhados pelos membros de uma organização que a distingue das demais. É por meio dos seus traços culturais que a organização define sua identidade, orienta e controla os comportamentos e atitudes dos que a integram (ROBBINS; JUDGE, 2014). Segundo Freitas (2005), é por meio da cultura organizacional que se transmite os valores, condutas e comportamentos aceitáveis, bem como as maneiras apropriadas de pensar e agir interna e externamente. 
Para Schein (2009, p.16), a cultura pode ser entendida como "um padrão de suposições básicas compartilhadas, que foi aprendido por um grupo à medida que solucionava seus problemas de adaptação externa e de integração interna". Deste modo, entende-se que se o padrão funciona, pode ser validado e ensinado aos novos membros como um modo adequado de perceber, pensar e sentir-se em relação a esses problemas.

ParaFleurye Sampaio (2002), alémdoconjunto devaloresepressupostos básicos que são expressos em elementos simbólicos com a capacidade de ordenar, atribuir significações e construir a identidade organizacional, a cultura organizacional contempla os elementos de comunicação e consenso que ocultam e instrumentalizam as relações de dominação. Robbins e Judge (2014), assim como Griffin e Moorhead (2006), corroboram que a cultura dominante possibilita o entendimento de ações consideradas apropriadas ou inapropriadas, destacando sua capacidade de orientar e modelar comportamentos.

No entanto, de acordo com Griffin e Moorhead (2006), mesmo que as empresas consigam articular e descrever seus valores, os mesmos só afetam intensamente a inovação da empresa quando os empregados os adotam como seus pressupostos. Desta forma, entende-se que as empresas atribuem seu sucesso a uma cultura profundamente arraigada. Ou seja, uma cultura organizacional consistente é essencial para o sucesso das organizações, uma vez que influencia na tomada de decisões, nos níveis de inovação e competição (interna), no atendimento aos clientes, bem como na qualidade de vida no trabalho.

A objetivação da cultura acontece, conforme Freitas (1991), por meio de seus elementos: valores, as crenças e pressupostos, os ritos, rituais e cerimônias, as estórias e mitos, os tabus, os heróis, as normas e a comunicação. Machado e Vasconcelos (2007), que buscaram a averiguação dos elementos da cultura organizacional que podem proporcionar e incentivar inovações, apresentam ainda os artefatos e símbolos. Estes aspectos, apresentados no quadro 1, fornecem um direcionamento para os relacionamentos organizacionais, oferecendo um caráter concreto à cultura.

Quadro 1 - Conceitos associados a cultura organizacional.

\begin{tabular}{|l|l|}
\hline Elementos & Definições \\
\hline \multirow{5}{*}{ Valores } & O que é importante para se atingir o sucesso. Observa-se que, em \\
& geral, as empresas definem alguns poucos valores, que resistem \\
ao teste do tempo, os quais são constantemente enfatizados. \\
& $\begin{array}{l}\text { Ainda que elas tendem a personalizar os seus valores, podemos } \\
\text { verificar que eles guardam algumas características comuns: } \\
\text { importância do Consumidor, padrão de desempenho excelente, } \\
\text { qualidade e inovação, importância da motivação intrínseca etc.. }\end{array}$ \\
\hline
\end{tabular}




\begin{tabular}{|c|c|}
\hline $\begin{array}{l}\text { Crenças e } \\
\text { pressupostos }\end{array}$ & $\begin{array}{l}\text { Geralmente usados como sinônimos para expressar aquilo } \\
\text { que é tido como verdade na organização. Quando um grupo ou } \\
\text { organização resolve seus problemas coletivos, esse processo } \\
\text { inclui alguma visão de mundo, algum mapa cognitivo, algumas } \\
\text { hipóteses sobre a realidade e a natureza humana. Se o sucesso } \\
\text { ocorre, aquela visão de mundo passa a ser considerada válida. Os } \\
\text { pressupostos tendem a tornar-se inconscientes e inquestionáveis. }\end{array}$ \\
\hline $\begin{array}{l}\text { Ritos, rituais e } \\
\text { cerimônias }\end{array}$ & $\begin{array}{l}\text { São exemplos de atividades planejadas que têm consequências } \\
\text { práticas e expressivas, tornando a cultura mais tangível e coesa. } \\
\text { Exemplos dessas atividades constituem grande parte do que é } \\
\text { desenvolvido pelos Departamentos de Recursos Humanos, como } \\
\text { nos casos de admissão, promoção, integração, demissão etc. }\end{array}$ \\
\hline Estórias e mitos & $\begin{array}{l}\text { Enquanto as estórias são narrativas de eventos ocorridos que } \\
\text { informam sobre a organização, os mitos referem-se a estórias } \\
\text { consistentes com os valores organizacionais, porém sem } \\
\text { sustentação nos fatos. Ambos preenchem funções específicas, } \\
\text { como: mapas, símbolos, etc.. }\end{array}$ \\
\hline Tabus & $\begin{array}{l}\text { Demarcam as áreas de proibições, orientando o comportamento } \\
\text { com ênfase no não-permitido. A literatura consultada não dá } \\
\text { maior atenção ao assunto, preferindo deter-se em casos de } \\
\text { tragédias organizacionais e sugerindo formas de se lidar com elas. }\end{array}$ \\
\hline Herois & $\begin{array}{l}\text { Personagens que incorporam os valores e condensam a força da } \\
\text { organização. Fala-se dos heróis natos e dos criados. E comum as } \\
\text { organizações chamadas culturas fortes exibirem os seus heróis } \\
\text { natos, como: Tom Watson, da IBM; Henry Ford, da Ford, entre } \\
\text { outros. }\end{array}$ \\
\hline Normas & $\begin{array}{l}\text { As regras que defendem o comportamento que é esperado, aceito } \\
\text { e sancionado pelo grupo, podendo estar escritas ou não. }\end{array}$ \\
\hline $\begin{array}{l}\text { Processo de } \\
\text { comunicação }\end{array}$ & $\begin{array}{l}\text { Inclui uma rede de relações e papéis informais que comportam } \\
\text { padres, fofoqueiros, conspiradores, contadores de estórias etc. } \\
\text { Ele desenvolve funções importantes como a de transformar o } \\
\text { corriqueiro em algo brilhante, podendo ser usado na administração } \\
\text { da cultura. }\end{array}$ \\
\hline $\begin{array}{l}\text { Artefatos e } \\
\text { símbolos }\end{array}$ & $\begin{array}{l}\text { Qualquer objeto, flâmula, bandeira, peso de papel, cortador, } \\
\text { quadro ou outros que sirvam de veículo de um significado da } \\
\text { inovação em processo, produto ou gestão. }\end{array}$ \\
\hline
\end{tabular}

Fonte: Adaptado pelos autores de: Freitas (1991), Machado e Vasconcelos (2007).

Griffin e Moorhead (2006), apontam três fatores relacionados à gestão da cultura organizacional. O primeiro está relacionado à compreensão dos valores existentes. $O$ segundo refere-se aos empregados que necessitam ser treinados de acordo com os valores culturais da organização. Por fim, o terceiro está direcionado a possibilidade de modificar a cultura da organização com o gerenciamento de símbolos e visibilidade das dificuldades externas, apoiandose na credibilidade da nova cultura organizacional instaurada. 
A partir disso, entende-se que para uma mudança organizacional se faz necessária a identificação dos aspectos que se deseja modificar. Da mesma forma, as pessoas que constituem as organizações devem se identificar com as novas regras ou os novos heróis. Deal e Kennedy (1982) afirmar que para uma mudança efetiva são necessárias mudanças reais no comportamento das pessoas da organização.

Em face disso, Dias (2003) aponta que os valores, desejos e interesses dos gestores interferem nos processos organizacionais. Ainda, o autor defende a importância da gestão de pessoas e do papel de cada indivíduo para a organização. Essa visão baseada em competências assemelha-se à do design que, segundo Mozota, Klöpsch e Costa (2011) insiste na inovação, na aprendizagem e na pesquisa. Contudo, entende-se que o conhecimento dos elementos da cultura organizacional torna-se um importante instrumento no que tange a inserção da gestão de design em uma organização.

\section{GESTÃO DE DESIGN}

O estudo da gestão de design teve origem na Grã-Bretanha em 1960 e, nesta época, se referia ao gerenciamento das relações entre os escritórios de design e os seus clientes. Neste contexto, o design passou a ser utilizado como um processo de gestão, visto que as empresas passaram a usufruir do seu caráter holístico, humanístico e inovador, essencial a competitividade e diferenciação (MOZOTA; KLÖPSCH; COSTA, 2011). Santos (2000) destaca que foi a partir dos anos 90 que o design se popularizou como um elemento estratégico, traduzindo-se em produtos diferenciados e organizações mais competitivas.

Martins e Merino (2011) compreendem a gestão de design como a organização e a coordenação das atividades de design, baseadas nos objetivos e valores da empresa, a fim de se planejar e coordenar as estratégias. Best (2012) e Mozota, Klöpsch e Costa (2011) ressaltam que o design pode ser um meio (ferramentas para solução de problemas) e um fim (quando colocado a serviço de objetivos corporativos). Assim, os autores apontam três níveis da gestão de design: operacional, tático e estratégico.

O nível operacional é a primeira etapa para a integração do design e refere-se a gestão de um projeto de design - orçamentos, briefings, gestão de equipes, avaliação de projetos, marketing, posicionamento e segmentação, ciclo de vida, portfolio, gestão da marca e construção de confiança no design da empresa. No que se refere ao nível tático, o design passa a ser entendido como uma função ou departamento independente. Assim, os profissionais passam a 
assumir funções táticas, que visam garantir o alinhamento das ações internas com as estratégias da organização (BEST, 2012; MOZOTA; KLÖPSCH; COSTA, 2011).

O nível estratégico estabelece elos entre design, comunicação corporativa e alta administração, estabelecendo uma nova visão baseada em princípios e estratégias de design. Neste nível é gerenciada a contribuição do design para a formulação da estratégia, definindo-se sua responsabilidade, liderança e contribuição à cultura organizacional. Para Merino e Ogava (2012), a gestão de design pode contribuir para a eficiência da organização e alinhamento dos seus objetivos e identidade. Todas as ações, produtos e comunicações devem consentir com estes propósitos, a fim de promover seu poder de diferenciação e potencial competitivo. Não obstante, sua cultura organizacional deve estar alinhada a estes propósitos, promovendo uma abertura para a inserção dos processos da gestão de design.

\section{GESTÃO DE DESIGN X CULTURA ORGANIZACIONAL}

No tocante a gestão de design nas empresas, Best (2012) ressalta que cabe a ela a identificação de formas de agregar ou criar valores tanto no âmbito do sistema produto-serviço, quanto na própria organização. Segundo Abreu (2016), entende-se como valor os atributos subjetivos que compreendem virtudes e qualidades da organização, que devem ser preservadas e incentivadas para que sejam reconhecidas interna e externamente.

Mozota, Klöpsch e Costa (2011) complementam o exposto ao contemplar a gestão do design como uma gestão de ativos, que agregam valor e, uma gestão de atitudes, que apoia a revisão de modelos mentais da empresa. Segundo os autores, a gestão de design relaciona-se a três áreas: a administração do valor do design, dos relacionamentos e dos processos. Deste modo, percebe-se que a cultura do design não se limita a práticas projetuais, compreendendo posturas operacionais e estratégicas que visam familiarizar o design e a gestão, bem como integrar o design e o contexto corporativo.

Dotado de competências estratégicas, o design passa a estar associado à liderança e a cultura organizacional da empresa, bem como na construção do conceito da identidade corporativa. "Se o processo de design não estiver presente no cotidiano da alta gerência e não fizer parte da sua maneira de pensar e gerir a organização, não haverá condições para que ele se desenvolva de forma adequada pelo resto da empresa" (SANTOS, 2000, p. 89). Schein (2009) destaca que a mudança cultural também pode prover da inserção de pessoas com novas suposições e diferentes experiências em diversas partes da organização. 
Outro obstáculo da construção de uma cultura voltada ao design se refere ao modelo de gestão tradicional, hierárquico e inflexível. De acordo com Mozota, Klöpsch e Costa (2011, p. 91), “a gestão do design está diretamente relacionada ao processo de mudança de um modelo de administração taylorista, hierárquico, para um modelo organizacional plano e flexível, que incentiva a iniciativa individual, a independência e a tomada de riscos".

Nesse sentido, os tradicionais controles e incentivos gerenciais baseados em recompensas financeiras podem limitar os benefícios do design, uma vez que se apresentam contrários ao processo de resolução de problemas por meio do design. No entanto, ressalta-se a necessidade da proteção e restrições de uma estrutura gerencial eficiente (BEST, 2012).

Contudo, apesar do reconhecimento da cultura da gestão do design, ainda é visível uma desorientação em relação a sua implementação. Segundo Best (2012), Gimeno (2000) e o Centro Português de Design (1997), não existem receitas prescritas para identificação e inserção da gestão de design nas empresas. São seus objetivos que norteiam o aproveitamento das competências do design, bem como das oportunidades provenientes de novas circunstâncias e exigências - internas ou externas.

Para Wolff (2010), a complexidade do processo de gestão do design está na escolha dos caminhos mais eficientes para cada empresa, para a elaboração e implementação das estratégias, passando pela idealização, análise de ambientes (internos e externos) e pelo modo de eleger ações ou direções. Nesse sentido, o conhecimento da cultura organizacional permite a identificação de potencialidades e fragilidades a serem trabalhadas para que se possa desenvolver uma cultura criativa e inovadora, propícia à inserção da gestão do design.

\section{PROCEDIMENTOS METODOLÓGICOS}

Este artigo apresenta uma pesquisa de natureza aplicada, pela abordagem qualitativa e, segundo seus objetivos, exploratória e descritiva. Segundo Creswell (2010, p. 26) "a pesquisa qualitativa é um meio para explorar e entender o significado que os indivíduos ou grupos atribuem a um problema social ou humano".

Quanto aos procedimentos técnicos, utilizou-se a pesquisa bibliográfica, elaborada a partir de material já publicado, como livros, artigos, periódicos e uma pesquisa documental (GIL, 1991). Além disso, realizou-se um estudo de caso na organização A. Essa técnica permite ao investigador o entendimento em profundidade de um determinado fenômeno, revelando nuances difíceis de serem visualizadas sob uma ótica superficial (YIN, 2010). 
A pesquisa segmenta-se em: fundamentação teórica (1); levantamento de dados secundários da empresa (2), entrevistas semiestruturadas com os empregados e gestores (3), análise de dados, discussão dos resultados (4) e considerações finais (5).

\subsection{Materiais e Métodos}

$\mathrm{Na}$ etapa de coleta de dados foram realizadas entrevistas semiestruturadas com gestores e empregados da empresa, visando a identificação de aspectos relacionados a cultura organizacional, propostos por Freitas (1991) e Machado e Vasconcelos (2007).

Foram entrevistados cinco (5) pessoas da empresa, dentre elas, dois (2) gestores e três (3) empregados. Os dados foram transcritos e organizados por agregação de categorias, sendo elas: valores; crenças e pressupostos; ritos, rituais e cerimônias; estórias e mitos; tabus; heróis; normas; processo de comunicação; artefatos e símbolos. Todos os aspectos éticos foram observados acompanhados de um termo de consentimento livre e esclarecido, mantendo a confidencialidade dos pesquisados. Por fim, na discussão dos resultados, foram correlacionados a fundamentação teórica, a fim de identificar as potencialidades e fragilidades da cultura organizacional no tocante a inserção da gestão de design.

\section{ESTUDO DE CASO}

O objeto deste estudo de caso caracteriza-se como como uma microempresa (ME), e mantém processos fabris semi artesanais. Suas atividades primárias constituem a fabricação e comercialização de produtos estofados - sofás, poltronas, puffs, camas, entre outros.

Fundada em 2008 na região do Vale do Itajaí, Santa Catarina, a empresa visou atender uma demanda nacional por produtos diferenciados, customizados e de elevado padrão de qualidade. A primeira coleção da empresa foi lançada em 2009 e nos anos seguintes foram lançados novos produtos, porém em menor escala. No ano de 2017 abriu sua primeira loja com foco no mercado regional, com vendas a consumidores finais.

Não existem setores bem definidos na empresa, mas pode-se classificá-los de uma forma geral como: gestão geral/gerência comercial, gestão administrativa e financeira, comercial e projetos e produção. A empresa 
conta com seis (6) empregados, sendo dois (2) gestores, um (1) designer e três (3) empregados na produção (encarregado de produção/ estofador, estofador, auxiliar de estofador e auxiliar de montagem de móveis).

\section{DISCUSSÃO DOS RESULTADOS}

Toda organização é constituída por elementos que norteiam seus padrões comportamentais. Esta cultura está intimamente relacionada a ideologia central da empresa, que contempla suas declarações estratégicas: visão, missão e valores. De acordo com Best (2012), o alinhamento destes elementos ajuda as organizações a saberem aonde irão e o que precisa ser feito. Nesse sentido, cabe ressaltar que, a partir dos estudos realizados, identificouse a inexistência destas declarações.

Além disso, percebeu-se uma estrutura hierárquica que, segundo Mozota, Klöpsch e Costa (2011) não condiz com a gestão do design. Os autores ressaltam que para sua inserção é necessário um processo de mudança voltado a um modelo organizacional plano e flexível, que incentiva a iniciativa individual, a independência e a tomada de riscos.

No entanto, ao investigar sobre a existência de uma cultura organizacional na empresa, os gestores A e B relatam a "inexistência" de uma cultura organizacional. O gestor A afirma que "não tem nenhuma cultura organizacional, infelizmente" e justifica por meio do pequeno porte da empresa. Assim, percebe-se que a cultura organizacional é entendida como um elemento externo que necessita ser implementado.

Para analisar a cultura organizacional, foram utilizados os elementos propostos por Freitas (1991) e Machado e Vasconcelos (2007): valores, crenças e pressupostos, ritos, rituais e cerimônias, estórias e mitos, tabus, heróis, normas, comunicação, artefatos e símbolos.

Observa-se que as empresas normalmente definem alguns poucos valores, que resistem ao tempo e são constantemente enfatizados. Freitas (2005) destaca que as empresas tendem a personalizar seus valores e, neste sentido, as entrevistas abordaram as preocupações e ações socioculturais, sustentáveis, de inovação e qualidade.

Quanto as ações sociais corporativas, Melo Neto e Brennand (2004) destacam Frederik, diretor de responsabilidade social da Ford, que afirma que estas devem estar baseadas em valores e práticas sociais corporativas. Ainda, apresenta exemplos como a governança corporativa, as condutas éticas, o foco na comunidade, a qualidade de vida no trabalho, o uso de tecnologias limpas, o respeito ao meio ambiente, a transparência e a confiança. 
Neste trabalho, o foco é dado a realização de ações que envolvam os empregados e a comunidade. Os gestores $A$ e $B$ relatam a ausência deste tipo de preocupação, justificada pela falta de recursos. Quanto ao desejo desta implementação, o gestor A destaca a importância de um "programa que fizesse com que os funcionários entendessem que a gente não fabrica um produto, mas constrói um estilo de vida".

Do mesmo modo, os empregados confirmam a ausência destas ações e relatam certo desinteresse. Questionado sobre a relevância das ações, o empregado B declara: "interessante seria, importante acho que não". Não obstante, o empregado $C$ afirma que " $[. .$.$] isso não se agrega à firma. O$ tempo que a gente perde com isso, a gente perde em serviço. [...] Cultura é cultura, serviço é serviço". Sobre a realização de eventos, o empregado A destaca o fato de não haver uma área propícia.

Diante do exposto, percebe-se que os empregados possuem uma cultura voltada ao trabalho desvinculado às atividades prazerosas e integrativas, ou seja, não compreendem os benefícios das ações socioculturais. Sendo assim, Melo Neto e Brennand (2004) explicam que é possível aumentar o nível de congruência quando a empresa introduz algumas ações internas de gestão socialmente responsável e valores básicos que traduzem o seu compromisso social com os seus empregados e dependentes. O autor cita como exemplo: maior participação dos empregados, maior transparência, melhorias salariais, maiores benefícios e maior diálogo.

No que tange às ações relacionadas à sustentabilidade, o gestor $\mathrm{A}$ destaca a superficialidade dada ao tema ao afirmar que "virou um conceito batido" e, no que se refere às práticas atuais, ressalta o descarte dos resíduos visando apenas o cumprimento das legislações. O gestor B relata que "os resíduos são separados e recolhidos por uma empresa que se responsabiliza pelo descarte correto. Os restos de espumas são recolhidos pelo fornecedor". Ainda, o gestor A aponta a importância da procedência da matéria prima e evidencia o uso de materiais com grande impacto ambiental, que desconhece substitutos.

Os empregados $\mathrm{A}, \mathrm{B}$ e $\mathrm{C}$ destacam que o processo produtivo gera poucos resíduos e a reciclagem é realizada quando possível. O empregado $B$ e $C$ destacam a importância da transformação de alguns resíduos em novos materiais, que poderiam ser usados na fabricação de outros produtos. $O$ empregado $\mathrm{A}$ e $\mathrm{C}$ relatam que retalhos de tecido são descartados e poderiam ser doados para associações que trabalham com artesanato. Diante do exposto, percebe-se a existência de um processo produtivo limpo e intencionalidades positivas por parte dos empregados, que vislumbram novas aplicações dos resíduos, demonstrando um pensamento criativo e uma valorização dos aspectos sustentáveis. 
No tocante a inovação, o gestor A afirma "[...] a gente trabalha no mercado com o que é quase o princípio básico a inovação, que é um produto de design. Design é inovação". O gestor B complementa relatando que os produtos possuem diferenciais. De acordo com Mozota, Klöpsch e Costa (2011) e Best (2012), o design em nível estratégico possibilita oportunidades de inovação e a exploração da identidade corporativa por meio do design.

Os empregados demonstram um desconhecimento sobre o conceito e as aplicações da inovação, no entanto, quando o conceito é exemplificado, relatam a existência de ações relacionadas à inovação, porém destacam que estas ainda são limitadas. Dodgson e Gann (2014) afirmam que uma das características da inovação é que ela pode ser encontrada em qualquer organização e seus resultados são uma melhoria em termos de conhecimento e avaliação, ou seja, são os processos que as organizações podem adotar como aprendizados.

No que diz respeito às possíveis melhorias que promovam a inovação, são citados os investimentos em maquinário atualizado, novos materiais e a consolidação de projetos existentes, não finalizados. O empregado A destaca a relevância de visitas às feiras: "teria bastante coisa em equipamento novo na área. Tem bastante materiais novos e bons".

Quanto ao investimento em novos equipamentos, o empregado $C$ relata "nós somos em poucos, acho que não compensaria". Este relato demonstra uma visão limitada, que dissocia inovação e MPEs. Em contrapartida, Dodgson e Gann (2014) destacam que não são apenas empresas de alta tecnologia que dependem da inovação em seus negócios e afirmam que ações deste gênero podem ser eficazes mesmo com um baixo custo. Porém, ressaltam o receio da mudança gerados pelos desafios da inovação, visto que podem gerar desconfortos às pessoas devido às transformações, induzindo incerteza, medo e frustração.

A este respeito, o empregado B destaca a existência de novos projetos, mas que estes não são concretizados. Ainda, ressalta a possibilidade do uso dos materiais de formas diferentes, possibilitando novos resultados. $O$ empregado $C$ menciona a necessidade de novos projetos, indo de encontro ao apontamento do gestor A, o qual destaca que para promover a inovação na empresa, "[...] a principal ação foi a contratação da designer que é a nossa responsável pela fábrica hoje". A este respeito, Neumeier (2010), aponta que se a organização pretende inovar, ela necessita construir uma cultura voltada à inovação.

Com relação a qualidade dos produtos, os gestores $A$ e $B$ destacam a escolha e aplicação das melhores matérias primas na produção das peças comercializadas, enfatizando que as mesmas são reconhecidas pela sua qualidade elevada. Os empregados A, B e C reforçam o exposto pelos gestores. $O$ empregado $B$, confirma a qualidade dos acabamentos e dos materiais, porém destaca a necessidade de melhorias na padronização da produção. 
Quanto às crenças e pressupostos, que expressam o que é tido como verdade na organização, verificou-se o comprometimento dos empregados bem como sua satisfação e orgulho em trabalhar na empresa. Segundo o gestor A, os empregados são comprometidos com a empresa, destacando a satisfação dos mesmos ao finalizarem os projetos especiais desenvolvidos, "[...] quando sai um produto dá pra ver que as pessoas ficam orgulhosas porque é bonito, diferente e poucas pessoas conseguem fazer". O empregado B relata que são poucos empregados, porém comprometidos. Em contrapartida, para o gestor $B$ e empregado $A$, o comprometimento não provém de todos.

Diante do fato dos empregados se orgulharem em trabalhar na empresa, o gestor A destaca: "acredito que a gente consegue fazer as pessoas felizes lá dentro". Nesse sentido, aponta a estabilidade financeira e a demanda de trabalho como justificativa. O gestor B acredita que os empregados se orgulham "por estarem fazendo produtos inovadores que precisam de uma mão-de-obra que é difícil aprender". Os empregados A, B e C afirmam que se sentem orgulhosos em trabalhar na empresa, enquanto o B justifica "foi aqui que eu aprendi uma profissão". O empregado C destaca a necessidade de uma comunicação interna mais eficiente, que possibilite o entendimento dos valores da empresa.

Em relação aos ritos, rituais e cerimônias que compõem a cultura organizacional, os pontos levantados foram a apresentação interna dos novos empregados e a realização de confraternizações. Quanto a isso, o gestor A relata que não existem práticas de apresentação. Os empregados corroboram. Os empregados $A$ e $B$ afirmam que esta prática seria importante, porém, o empregado $B$ ressalta a importância de ser um evento rápido e objetivo, diferente da prática acontecia na empresa anteriormente.

No tocante a ocorrência e importância das confraternizações, o empregado $B$ destaca que já houveram eventos, mas ressalta "[...] não sei se é importante, mas é uma coisa que pro funcionário é diferente". O empregado C destaca que traria o gestor para mais perto do funcionário. Diante do exposto percebe-se que a prática de confraternizações já fez parte da cultura da empresa, porém atualmente não se faz presente. Contudo, verificou-se que tanto os gestores como os empregados percebem a relevância destas ações.

No que tange as estórias e os mitos, os gestores e empregados foram questionados sobre o compartilhamento de estórias e práticas. Nesse sentido, o gestor A declara que "a história sempre é contada e tenta-se passar para os funcionários que a história faz parte do conceito da marca $[\ldots]$ ". O gestor B reforça que "a história é compartilhada e com isso podemos melhorar a nossa produção". Os empregados não apresentam grande clareza em relação às histórias, demonstrando certa contradição ao exposto pelos gestores.

Quanto aos tabus foram observadas ações reprovadas na empresa, por gestores e empregados. Nesse sentido, o gestor A afirma que reprova 
"[...] o não devido entendimento do produto que a gente fabrica e os cuidados necessários". O empregado A destaca ações que reprova, como "muita conversa e o uso do celular". O C destaca as brincadeiras em momentos inadequados como uma ação negativa que dispersa a sua concentração nas atividades. $\mathrm{O}$ empregado $B$ também relata a ocorrência das brincadeiras, porém não atribui um fator negativo a elas, porém destaca a reprovação desta prática por parte dos gestores.

Os heróis se referem às pessoas associadas a ações positivas. O gestor A cita a designer como a personagem que incorpora os valores da organização, "[...] tem formação acadêmica, tem conhecimento e vontade para colocar em prática tudo". Ainda, dois dos empregados citam a designer e todos destacam o comprometimento do empregado $A$.

No que se refere às normas, a empresa não apresenta regras escritas, porém possui uma programação semiestruturada da produção. Quanto a organização das atividades internas, o gestor A destaca a intenção do aprimoramento da rotina e destaca a imaturidade desta organização. O empregado $A$ confirma a existência da rotina, enquanto o empregado $C$ aponta a importância das tarefas pré-estabelecidas para a organização e eficiência do trabalho. Em contrapartida, o empregado B relata muitas interrupções na rotina estabelecida, destacando a possibilidade de desconfortos e erros.

Ao analisar o processo da comunicação, foram questionados sobre a abertura e estímulo ao compartilhamento de ideias. O gestor $A$ relata que "sempre que é fabricado um novo produto a gente estimula os funcionários a dar ideias de um jeito mais fácil de concebê-lo". O empregado A destaca que ele é o mais estimulado a dar ideias, enquanto o empregado $B$ relata situações em que apresentou novas soluções. $O$ empregado $C$ destaca suas contribuições técnicas e afirma haver uma abertura para a apresentação de novas ideias pelo empregado A. Diante disso, percebe um bom relacionamento entre os empregados, bem como a troca de informaç̃oes e ideias. Estas são posturas de empresas inovadoras que, segundo Terra (2007), estimulam a geração de ideias, garantem um retorno, favorecem a colaboração, reconhecem e premiam os que sugerem coisas novas e trabalham para que as ideias se concretizam e gerem valor para a organização.

Quanto aos artefatos e símbolos, as entrevistas abordaram a importância e o uso de uniformes e materiais de comunicação. Questionado sobre a importância do uso de uniformes, o gestor A destaca que "faz parte da construção da cultura da empresa. O uniforme e todo o material gráfico dá nome e conceitua o que a gente quer fazer". Da mesma forma, os empregados A, B e C concordam sobre a relevância do uso do uniforme para a divulgação da imagem da empresa, economia de roupas pessoais e o estabelecimento de uma imagem mais profissional diante dos visitantes da empresa. 
Ainda sobre os artefatos, destacam-se a aplicação da identidade corporativa interna. Nesse sentido, o gestor A enfatiza "como o uniforme, o logo é importante, ele é o nome. Ele identifica e passa todo o conceito da empresa. [...] a marca, para ser reconhecida, tem que ser aplicada em toda a papelaria e principalmente no produto". Neste contexto, Mozota, Klöpsch e Costa (2011) ressalta que a inovação gráfica é o resultado visual da mudança e que o seu sucesso depende da sinergia entre o projeto e seu contexto.

\section{CONCLUSÕES}

Diante do exposto, foi possível compreender que para ser efetiva, a introdução da gestão de design deve ser acompanhada de uma mudança cultural na organização. Deste modo, uma empresa que pretende incluir o design em sua estratégia, necessita compreender as características da sua cultura organizacional a fim de identificar pontos críticos e favoráveis ao desenvolvimento de uma cultura direcionada ao design. Assim, cumprindo o objetivo proposto, apresenta-se uma síntese do diagnóstico da empresa, com uma escala de suas potencialidades e fragilidades, conforme a figura 1.

Figura 1 - Diagnóstico da cultura organizacional da empresa.

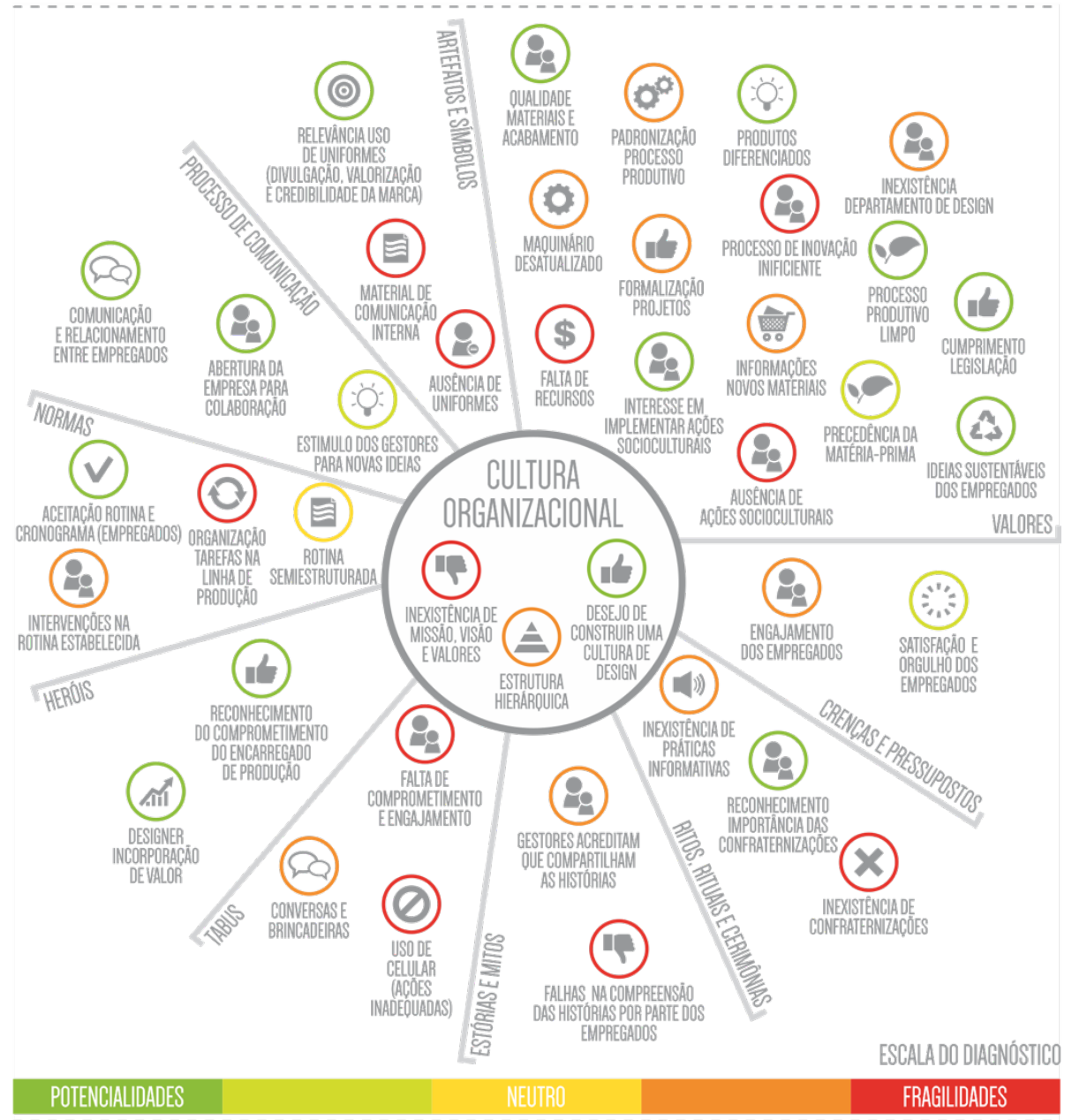

Fonte: Os autores (2017).

Projética, Londrina, v.10, n.3, p. 27-46, jul./dez. 2019 
Apesar do estudo proposto ter identificado que não existe uma cultura de design formalizada, a empresa apresenta várias potencialidades que podem favorecer a inserção de seus valores. Cabe destacar aqui o desejo dos gestores em construir uma cultura com esse direcionamento, bem como seu interesse em compartilhar os valores da empresa com os seus empregados, que demonstram certa abertura. Porém, esse processo ainda se apresenta de forma inconsistente e requer maior atenção e investimentos.

No que se refere aos valores intrínsecos da cultura de design, como a inovação a qualidade e o foco nas pessoas, a empresa apresenta uma série de potenciais, como a valorização do design, a concepção e desenvolvimento de produtos diferenciados, a abertura para inovação, o compartilhamento de ideias, a percepção da qualidade dos produtos, bem como o interesse em ações socioculturais e sustentáveis. A partir de um viés mais técnico, destacam-se potencialidades da empresa em relação ao seu processo produtivo limpo, ao estabelecimento de uma rotina de trabalho e a sua aceitação pelos empregados, além da importância dada à contratação de um profissional da área de design.

Quanto a consistência da cultura organizacional, destaca-se a necessidade e importância de uma narrativa que englobe seus heróis, as recompensas aos membros em destaque, os meios de comunicação interna que transmitem as mensagens, normas, deveres e direitos. Porém, foi neste âmbito que foram identificadas as maiores fragilidades da empresa, destacando-se algumas falhas na comunicação interna, que aparecem refletidas na falta de clareza com que os empregados compreendem conceitos e valores vistos como básicos e essenciais pelos gestores.

Não obstante, outro desafio percebido relaciona-se aos valores pessoais de alguns empregados, que apresentam dificuldades para associar o trabalho a ações prazerosas. Esses valores arraigados podem dificultar a inserção de ações socioculturais, de confraternização e voltadas à inovação, uma vez que trariam uma atmosfera com menor rigidez. Desta forma, percebe-se que os valores das pessoas que compõem a organização têm reflexo direto na construção e manutenção da sua cultura.

Nesse sentido, entende-se que a inclusão da gestão de design é facilitada no momento em que os gestores e empregados entendem os seus impactos positivos na organização. Deste modo, percebe-se que os valores compartilhados pela cultura organizacional se tornam poderosos instrumentos para orientação e modelagem dos comportamentos. Porém, são necessários esforços de ambas as partes para que as iniciativas sejam concretizadas. A este respeito, destaca-se uma imaturidade da empresa na formalização de ações positivas iniciadas, evidenciando-se um desafio à ser superado.

Contudo, conclui-se que uma mudança efetiva na cultura organizacional requer a identificação dos aspectos que se deseja manter e modificar, bem 
como de mudanças reais no comportamento das pessoas da organização. Dessa maneira percebe-se que os estudos sobre a cultura organizacional ganham relevância nos meios científicos e corporativos, tendo em vista que a cultura diz muito sobre as organizações. A cultura associada à gestão de design possibilita fundamentar práticas, políticas e processos com base nos potenciais do design, permitindo uma organização coesa, com valores compartilhados que propiciam engajamento, excelência administrativa e um ambiente interno criativo e inovador.

Diante das consideráveis contribuições deste tema, para trabalhos futuros, sugere-se a investigação de possíveis ações práticas capazes de estimular e auxiliar as organizações na construção de uma cultura voltada ao design. 


\section{REFERÊNCIAS}

ABREU, Milla dos S. P. Breve discurso sobre a problematização social das diferenças: uma abordagem prática sobre os valores da organização e do ser. In: CONGRESSO NACIONAL DE EXCELÊNCIA EM GESTÃO, 12., 2016, Rio de Janeiro, RJ. Anais [...]. Rio de Janeiro: FIRJAN, 2016. p. 1-15. Disponível em: http://www.inovarse.org/node/4762. Acesso em: 15. abr. 2017.

BES, Fernando T. de; KOTLER, Philip. A bíblia da inovação: princípios fundamentais para levar a cultura da inovação contínua às organizações. São Paulo, Leya, 2011.

BEST, Kathryn. Fundamentos da gestão de design. Porto Alegre: Bookman, 2012.

CENTRO PORTUGUÊS DE DESIGN. Manual de gestão do design. Porto: Porto Editora, 1997.

CRESWELL, John W. Projeto de pesquisa: métodos qualitativo, quantitativo e misto. 3. ed. Porto Alegre: Artmed, 2010.

DEAL, Terrence. E.; KENNEDY, Allan. A. Corporate cultures: the rites and rituals of corporate life. Reading, MA: Addison-Wesley, 1982.

DIAS, Reinaldo. Cultura organizacional. Campinas: Átomo \& Alínea, 2003.

DODGSON, Mark; GANN, David. Inovação. Porto Alegre: L\&PM Pocket, 2014.

FLEURY, Maria Tereza Leme; SAMPAIO, Jader dos Reis. Uma discussão sobre cultura organizacional. In: FLEURY, Maria Tereza Leme (org.). As pessoas na organização. São Paulo: Editora Gente, 2002. p. 283-294.

FREITAS, Maria E. Cultura organizacional: grandes temas em debate. Revista de Administração de Empresas, São Paulo, SP, v. 31, n. 3, p. 73-82, jul./set.1991. Disponível em: http://www.scielo.br/pdf/rae/v31n3/v31n3a0>. Acesso em: 12 mar. 2017.

FREITAS, Maria E. Cultura organizacional: identidade, sedução e carisma? 4. ed. Rio de Janeiro: Editora FGV, 2005.

GIL, Antônio C. Como elaborar projetos de pesquisa. São Paulo: Atlas, 1991.

GIMENO, José Maria Ivánez. La gestión del diseño en la empresa. Madrid: McGraw-Hill de Management, 2000

GRIFFIN, Richy W.; MOORHEAD, Gregory. Fundamentos do comportamento organizacional. São Paulo: Ática, 2006.

MACHADO, Denise Del Prá Netto; VASCONCELLOS, Marcos Augusto. Organizações inovadoras: existe uma cultura específica que faz parte deste ambiente? REGE: Revista de Gestão, São Paulo, v. 14, n. 4, p. 15-31, 2007. 
MARTINS, Rosane F. de F.; MERINO, Eugenio A. D. A gestão de design como estratégia organizacional. 2. ed. Londrina: EDUEL, 2011.

MELO NETO, Francisco P. de; BRENNAND, Jorgiana. M. Empresas socialmente sustentáveis: o desafio da gestão moderna. Rio de Janeiro: Qualitymark, 2004.

MERINO, Eugenio Andrés Díaz; OGAVA, Camila de Cássia das Dores. Inovação como fator de fortalecimento de microempresas e pequenas empresas através da gestão de design. In: CONGRESSO NACIONAL DE EXCELÊNCIA EM GESTÃO, 8., 2012, Rio de Janeiro, RJ. Anais [...]. Rio de Janeiro: FIRJAN, 2012. p. 1-12. Disponível em: http://www.inovarse.org/sites/ default/files/T12_0454_3051.pdf. Acesso em: 15. abr. 2017.

MOZOTA, Brigitte B. de; KLÖPSCH, Cássia; COSTA, Filipe C. Xavier da. Gestão do Design: Usando o design para construir valor de marca e inovação corporativa. Porto Alegre: Bookman, 2011.

NEUMEIER, Marty. A empresa orientada pelo design. Porto Alegre: Bookman, 2010.

ROBBINS, Stefhen P.; JUDGE, Timothy A. Fundamentos do comportamento organizacional. 12. ed. São Paulo: Pearson Prentice Hall, 2014.

SANTOS, Flávio A. O design como diferencial competitivo: o processo de design desenvolvido sob o enfoque da qualidade e da gestão estratégica. Itajaí: Ed. da UNIVALI, 2000.

SCHEIN, Edgar H. Cultura organizacional e liderança. São Paulo, Atlas, 2009.

SEBRAE (Brasília) - Serviço Brasileiro de Apoio às Micro e Pequenas Empresas (org.). Participação das micro e pequenas empresas na economia brasileira. Brasília: Sebrae, 2015. Disponível em: http://www. bibliotecas.sebrae.com.br/chronus/ARQUIVOS_CHRONUS/bds/bds.nsf/ e55cdb1932bc40120b21bf4d277bb6ea/\$File/5307.pdf. Acesso em: 18 abr. 2017.

SEBRAE (Santa Catarina). Serviço Brasileiro de Apoio às Micro e Pequenas Empresas (org.). Santa Catarina em números: macrorregião Vale do Itajaí. Florianópolis: Sebrae, 2013. Disponível em: http://www.sebrae.com.br/ Sebrae/Portal\%20Sebrae/Anexos/Macrorregiao\%20-\%20Vale\%20do\%20 Itajai.pdf. Acesso em: 18 mar. 2017.

TERRA, José C. C. (org.). Inovação: quebrando paradigmas para vencer. São Paulo: Saraiva, 2007.

WOLFF, Fabiane. Sistemática de avaliação da gestão de design em empresas. 2010. Dissertação (Mestrado em Engenharia de Produção) - Universidade Federal do Rio Grande do Sul, Porto Alegre, 2010. 


\section{FORCELINI, Franciele; et al.}

YIN, Robert. K. Estudo de caso: planejamento e métodos. 4. ed. Porto Alegre: Bookman, 2010.

Data de submissão: 2017-11-27

Data de aceite: 2019-04-03 